University of Wollongong

Research Online

Faculty of Engineering and Information

Faculty of Engineering and Information

Sciences - Papers: Part A

Sciences

$1-1-2015$

Benefits of online health education: perception from consumers and health professionals

Khin Than Win

University of Wollongong, win@uow.edu.au

Naffisah Mohd Hassan

University of Wollongong,nmh876@uowmail.edu.au

Andrew Bonney

University of Wollongong, abonney@uow.edu.au

Donald Iverson

University of Wollongong, iverson@uow.edu.au

Follow this and additional works at: https://ro.uow.edu.au/eispapers

Part of the Engineering Commons, and the Science and Technology Studies Commons

Research Online is the open access institutional repository for the University of Wollongong. For further information contact the UOW Library: research-pubs@uow.edu.au 


\title{
Benefits of online health education: perception from consumers and health professionals
}

\author{
Abstract \\ With the advancement in technology and availability of the Internet, online health education could become \\ one of the media for health education. As health education is to persuade patients on health behavioural \\ change, understanding perceived benefits of online health education is an important aspect to explore. \\ The aim of this study is to explore consumers and health professionals opinion on online health \\ education. Literature review was conducted and identified the benefits of online health education (OHE). \\ Survey was conducted to health consumers and health professionals. Descriptive analyses were \\ performed using SPSS Version 19.0. The analysis of the literature has identified a set of 12 potential \\ benefits of OHE which had been used to understand the perceptions of the effectiveness of OPE sites and \\ these have been validated in the study. This study has the practical implication as the study identified \\ OHE effectiveness, which definitely can assist health practitioners on health education, which can lead to \\ better health outcome.

\section{Disciplines} \\ Engineering | Science and Technology Studies

\section{Publication Details} \\ Win, K. T., Mohd Hassan, N., Bonney, A. D. \& Iverson, D. C. (2015). Benefits of online health education: \\ perception from consumers and health professionals. Journal of Medical Systems, 39 (3), 27-1-27-8.
}




\title{
Benefits of online health education: perception from consumers and health professionals
}

\author{
Khin Than Win, Naffisah Mohd Hassan, Andrew Bonney, Don Iverson
}

\author{
Corresponding Author \\ Dr. Khin Than Win \\ School of Information Systems and Technology \\ University of Wollongong \\ Northfields Avenue \\ Wollongong 2522 \\ Australia \\ Tel: 61242214142 \\ Email:win@uow.edu.au
}

\begin{abstract}
With the advancement in technology and availability of the Internet, online health education could become one of the media for health education. As health education is to persuade patients on health behavioural change, understanding perceived benefits of online health education is an important aspect to explore. The aim of this study is to explore consumers and health professionals opinion on online health education. Literature review was conducted and identified the benefits of online health education (OHE). Survey was conducted to health consumers and health professionals. Descriptive analyses were performed using SPSS Version 19.0. The analysis of the literature has identified a set of 12 potential benefits of OHE which had been used to understand the perceptions of the effectiveness of OPE sites and these have been validated in the study. This study has the practical implication as the study identified OHE effectiveness, which definitely can assist health practitioners on health education, which can lead to better health outcome.
\end{abstract}

Keywords: health education, online health education, benefits, consumers, health professionals 


\section{Introduction}

Health education to patient is an integral part of healthcare management [1]. With the advancement in technology and availability of the Internet, health education could be disseminated to patients through online media as well. Traditionally health education is delivered in the medium of face to face communication by health professionals and health educators to healthcare consumers and this has been proven effective. However, more flexible health education can be offered online and this method can complement the current face-to-face education. In many cases, when healthcare consumers understand their disease status, complications and their management, they become more involved in their healthcare [2]. This increase in consumer knowledge may then lead to improved health outcomes $[3,4]$.

Additional advantages of online health education include the ability of consumers to access health education material in their own time and the ability to facilitate disease self-management [2].

It is undeniable that the web has become a widely-used resource for people seeking health information. However, the quality of this Online Health Information (OHI) [5] has the potential to critically affect health outcomes for many users [6]. One widely expressed concern about $\mathrm{OHI}$ is that patients can freely access information about their disease from both reliable and unreliable sources [7,8] which could mislead readers, especially if the $\mathrm{OHI}$ is outdated [7], or comes from a non-validated source $[9,10]$. Doctors have expressed concerns in the literature that confusing online information may create a need for increased educational input so that the mis-information obtained online will not interfere with treatment goals [11]. Online health education (OHE) refers to online material that is specifically tailored to the needs of patients who suffer from a specific disease [12] . Whilst the potential benefits of OHE have been widely published in the literature, there are studies indicating concerns from health professionals regarding consumers relying on online material. Therefore, perceptions of health professionals' opinion on OHE needs to be explored.

One of the well-known theories in health behavioural research, the health belief model [13] indicated that perceived benefits of problems, perceived benefits of action will lead to health behaviour change. Since OHE is to promote healthy behaviour towards consumers[14], it is important to explore perceived benefits of OHE from consumers.

Therefore, this study aims to explore perceptions of health professionals' and health consumers' opinion on online health education and compare their opinion on benefits of OHE. Literature review on benefits of online health education has been conducted and online survey was conducted to explore the opinions.

\section{Methodology}

A literature review was conducted by accessing relevant databases such as Medline, PubMed, IEEE Explore, Scopus, to obtain articles published from 1995 
to 2013. Eligibility criteria for papers to be included in the study were: publication in English; cited, scholarly, peer-reviewed, article from an academic journal; and discuss the benefits of OHE. A combination of terms including "online", "web", "websites", "Internet”, "patient education”, "health education”, "benefit”, "advantages", "features", were used as keyword combinations. The initial results comprised 1021 titles on health education. Re-examination and cross checking of the bibliographies of the articles were also performed. Benefits of OHE were identified from thorough literature review. Afterwards, pilot study with 20 participants was conducted. To ensure that the responses are reliable and valid for the study quantitative data analysis was performed through involving more participants. A list of chronic disease websites in Australia were gathered through observation and a formal email were sent to seek information about the sites membership which comprise of health professional and patient/carer of chronic disease. A list of 27 chronic disease websites were identified and contacted to get permission. 7 websites gave positive feedback to provide help in gathering data. Descriptive analyses were performed using SPSS Version 19.0. Respondents for survey included health professionals and healthcare consumers. A total of 215 respondents took part in the survey, which include 141 patient/carer and 74 health professionals of which $41.8 \%$ is 55 years or above.

\section{Results}

A summary of the findings from the initial literature review study is presented in Table 1. Forty-five studies in various diseases mentioned OHE improves health outcomes and improved health education and knowledge acquisition. Among these studies, fifteen studies that used randomized controlled trials, three studies that used quasi experimental methods and the three studies that used cross sectional methods indicated that OHE offered better health education and improved patients' knowledge of their diseases. Followed by forty-six studies, which mentioned OHE can help to improve self-care behaviour and self-care management. Thirty-eight studies of chronic diseases suggest that OHE contributes in improving patient emotional states and satisfaction. Out of thirtyeight studies, eleven studies that used randomized controlled groups and three studies that used cross sectional surveys report that OHE offered patients better emotional state and improved their satisfaction. Thirty-six studies including eleven randomized control studies and three experimental studies show that that OPE improved quality of interaction with physician, followed by thirty-five studies, agreed that OHE helps in terms of time and cost effectiveness. Twentyeight papers regarding chronic disease mentioned OHE helps to increased patient confidence towards treatment, followed by improved patient awareness with twenty-four studies. Benefits in such as reduce hospitalizations (twenty-three studies), easy access of educational material (twenty-two studies) and improved social support (twenty studies) were also gathered in OHE were also mentioned in regards with $\mathrm{OHE}$.

OHE aims to improve health literacy, which is one of the most important elements in improving health outcomes [15]. [15] concluded that health outcome measures include reduced morbidity, reduced disability. Several researchers found that patients who received effective OHE regarding their disease tended to improve 
their health outcomes [16,17]. Positive effects were found among patients undergoing OHE on diabetes education [16]. Three papers which used a randomized controlled trials showed that diabetes OHE improved glycemic control among adults with diabetes [16,17]. Another 13 papers concluded that OHE does improve overall patient health outcomes. Continuing care and OHE help maintain good control of the disease and prevent complications. OHE can continually provide "active health" since it can deliver educational messages to patients at the time of their choice without waiting to be informed.

The right education materials produce well-educated and knowledgeable health consumers, which can lead to better health outcomes. [18] found that in a study of patients with asthma, the computer-based and online educational program group had significantly better results than those receiving no computerized education. Reliable online health websites offer up-to-date information and cutting edge knowledge for various diseases. It helps patients understand what they are dealing with and reduce the possibility of harmful or ineffective self-treatment.

Table 1: Studies on benefits of online health education

\begin{tabular}{|c|c|c|c|c|c|c|c|c|c|c|c|c|c|}
\hline 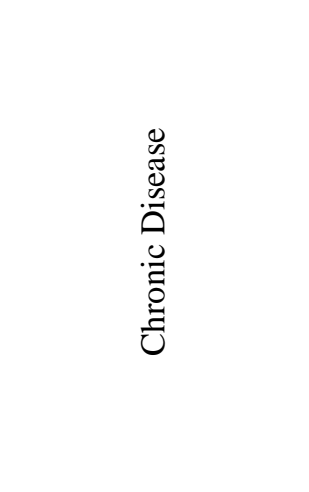 & 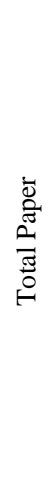 & 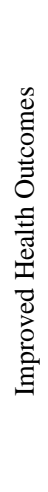 & 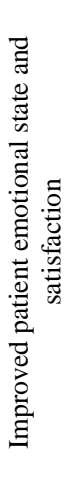 & 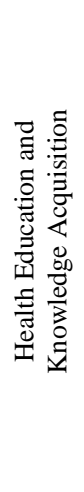 & 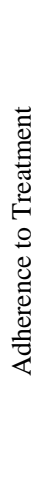 & 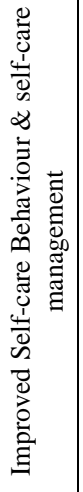 & 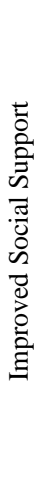 & 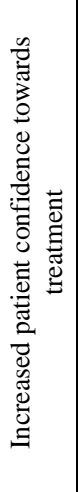 & 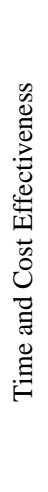 & 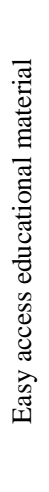 & 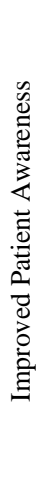 & 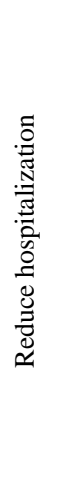 & 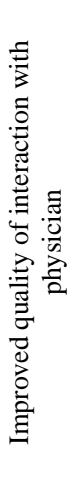 \\
\hline Chronic Bowel (2) & $\sqrt{ }$ & & $\sqrt{ }$ & $\sqrt{ }$ & $\sqrt{ }$ & $\sqrt{ }$ & & & $\sqrt{ }$ & $\sqrt{ }$ & & & \\
\hline Chronic Kidney (2) & $\sqrt{ }$ & $\sqrt{ }$ & & & & $\sqrt{ }$ & & & & & & & \\
\hline $\begin{array}{l}\text { Epilepsy and } \\
\text { Seizures (2) }\end{array}$ & $\sqrt{ }$ & $\sqrt{ }$ & $\sqrt{ }$ & $\sqrt{ }$ & & $\sqrt{ }$ & $\sqrt{ }$ & & & & & & \\
\hline Lower Back Pain (2) & $\sqrt{ }$ & & $\sqrt{ }$ & & $\sqrt{ }$ & $\sqrt{ }$ & & & & & & & \\
\hline Chronic Asthma (3) & $\sqrt{ }$ & $\sqrt{ }$ & & $\sqrt{ }$ & $\sqrt{ }$ & $\sqrt{ }$ & $\sqrt{ }$ & & $\sqrt{ }$ & & & $\sqrt{ }$ & $\sqrt{ }$ \\
\hline Cardiovascular (3) & $\sqrt{ }$ & $\sqrt{ }$ & $\sqrt{ }$ & $\sqrt{ }$ & $\sqrt{ }$ & $\sqrt{ }$ & & $\sqrt{ }$ & $\sqrt{ }$ & & & $\sqrt{ }$ & $\sqrt{ }$ \\
\hline $\begin{array}{l}\text { Anxiety, Depression } \\
\text { and Mental Illness } \\
\text { (3) }\end{array}$ & $\sqrt{ }$ & $\sqrt{ }$ & $\sqrt{ }$ & $\sqrt{ }$ & $\sqrt{ }$ & & & $\sqrt{ }$ & & $\sqrt{ }$ & $\sqrt{ }$ & & $\sqrt{ }$ \\
\hline Obesity (4) & $\sqrt{ }$ & $\sqrt{ }$ & $\sqrt{ }$ & $\sqrt{ }$ & & $\sqrt{ }$ & $\sqrt{ }$ & & $\sqrt{ }$ & & $\sqrt{ }$ & & $\sqrt{ }$ \\
\hline Cancer (5) & $\sqrt{ }$ & $\sqrt{ }$ & $\sqrt{ }$ & $\sqrt{ }$ & $\sqrt{ }$ & & $\sqrt{ }$ & $\sqrt{ }$ & & & & & \\
\hline Diabetes Mellitus (6) & $\sqrt{ }$ & $\sqrt{ }$ & & $\sqrt{ }$ & $\sqrt{ }$ & $\sqrt{ }$ & $\sqrt{ }$ & & $\sqrt{ }$ & & & & $\sqrt{ }$ \\
\hline
\end{tabular}




\begin{tabular}{c|c|c|c|c|c|c|c|c|c|c|c|c|c}
\hline $\begin{array}{c}\text { Others Chronic } \\
\text { Diseases (17) }\end{array}$ & $\sqrt{ }$ & $\sqrt{ }$ & $\sqrt{ }$ & $\sqrt{ }$ & & $\sqrt{ }$ & & $\sqrt{ }$ & $\sqrt{ }$ & $\sqrt{ }$ & $\sqrt{ }$ & $\sqrt{ }$ & $\sqrt{ }$ \\
\hline
\end{tabular}

The aims of chronic disease health education are to make patients aware of the disease, build positive attitudes, and make them active partners in therapy or treatment. In Australia, more than 8 diabetes websites regarding diabetes information are available to the general public and serve to educate diabetes patients with state-of-the-art knowledge in order to promote self-care behaviour among patients. Through the Web, those with chronic diseases learn how to manage their conditions correctly. For instance, after seeking information from disease-specific websites, one-third of chronic disease sufferers reported taking their medications more regularly [19].

OHE can improve a patient's emotional state and satisfaction. [20,21] observed that learning is a way for patients to gain some control of the situation and, thus, decreases anxiety. The 11 studies that used randomized controlled groups and the 3 studies that used cross sectional surveys report that OHE offered patients better emotional state and improved their satisfaction. Through increased knowledge, patients develop healthier lifestyles. Usually, patients with chronic diabetes suffer from depression and anxiety as they are worried about their medical conditions. Educating the patients can help stabilize their emotional state but from the patients' perspectives, diabetes education consists of an overwhelming amount of new information, which is often presented on only one occasion. The consumers want their education to be a continuous process [11]. The Web seems to be an effective medium in this respect because they can access information anytime, anywhere, repeatedly.

Patients, who use the Web, spend less time asking about things that are unrelated to their diseases and also less time is needed to explain about misleading medical recommendations and theories that frustrate both patients and their physicians. By using OHE, time spent with patients discussing treatment can be saved, compared to those seeking information solely from their physicians. This leads to higher consumer satisfaction [22,23] because health consumers usually value the physician's advice and guidance. Patients who get reliable medical information are more likely to make better use of the health care system because they know when they are in need or not in need of medical treatment. Well-educated patients make better patients because they tend to be more open-minded and realistic and they also become more proactive in managing their diseases [23].

It is believed that a consumer, who is educated about his or her health-related problems, will have better adherence to treatments [24]. From the consumers' point of view, by knowing what they are going to go through helps them to prepare themselves for their treatments. Without knowing what they are going to face, consumers might be reluctant to cooperate in their treatments, which could make it more difficult to cure or improve their medical conditions. Nonetheless some chronic disease patients refused to undergo treatment after finding out what they were going to face during treatment [25]. For example, a number of cancer patients refused treatment after viewing an online multimedia video explaining about their treatment. Therefore, tailoring information according to needs is important and consumers' perception towards the benefits of OHE is important. 
OHE has been shown [26] to be more cost effective as it reduces patients' expenses to travel to the hospital or medical centre. It also saves patients' time by reducing travel time, especially during peak time [27]. The Web offers new, inexpensive, and rapid methods to provide and enhance a patient's asthma education [28]. Researchers in the study observed that, unlike traditional patient handouts, the Web offers patients interactivity and engagement, which should enhance their learning and understanding. In the United States, those who suffer from chronic illnesses make up $70 \%$ of medical costs and $80 \%$ of deaths; improving the way their conditions are managed holds great potential for cost savings and reduced mortality rates [19].

Table 2: Perceived benefits of online health education

\begin{tabular}{|c|c|c|c|}
\hline Perceived Benefits & Studies & Mean & Std. Deviation \\
\hline $\begin{array}{l}\text { BH1. Improved Health Education and } \\
\text { Knowledge Acquisition }\end{array}$ & {$[16,18,29]$} & 4.40 & .50262 \\
\hline BH2. Improved Patients Awareness & {$[19,30,31]$} & 4.10 & .78807 \\
\hline $\begin{array}{l}\text { BH3. Increased Patient Confidence towards } \\
\text { treatment }\end{array}$ & [32-34] & 3.90 & .71818 \\
\hline $\begin{array}{l}\text { BH4. Improved self-care behaviour and Self- } \\
\text { care management }\end{array}$ & {$[35,19,36]$} & 3.85 & .67082 \\
\hline BH5. Improved Health Outcomes & {$[15,16,37,38]$} & 3.75 & .85070 \\
\hline BH6. Improved Adherence to treatment & {$[39,24,11]$} & 4.00 & .72548 \\
\hline BH7. Reduce Hospitalizations & [40], [41,11] & 3.20 & .89443 \\
\hline $\begin{array}{l}\text { BS1. Improved quality of Interaction with } \\
\text { Physician }\end{array}$ & {$[42,11,31]$} & 3.85 & .74516 \\
\hline BS2. Easy Access to Educational Material & {$[12,11]$} & 4.30 & .57124 \\
\hline BS3.Time effectiveness & {$[19,26]$} & 3.95 & .82558 \\
\hline BS4. Cost effectiveness & {$[19,26]$} & 3.95 & .82558 \\
\hline BS5.Improved Social Support & [43-45] & 3.75 & .96655 \\
\hline $\begin{array}{l}\text { BS6. Improved Patient Emotional State and } \\
\text { Satisfaction }\end{array}$ & {$[46,23,45]$} & 3.75 & .78640 \\
\hline
\end{tabular}

Following the recommended criteria of EFA for perceived benefits constructs, the statistical analysis shows: (1) the value of KMO is 0.911 (which exceeds the recommended value of 0.70 ), so the questions could be suitable for performing Exploratory Factor Analysis. (2) The value of Bartlett's Test of Sphericity is also very significant (Chi-Square is 1529.737 , $\mathrm{df}$ is $78, \mathrm{p}=0.000$ ), it shows that these questions support the factorability of the correlation matrix. For criteria (3) and (4), we only keep items with values of communality and its factor loading is greater than 0.4 for determining which question makes a significant contribution to its related constructs. Table 3 below shows the result of EFA for perceived benefits constructs. 
Based on the results of statistical analysis, the values of communality for DF items are greater than 0.4 except for one items (BS2), hence, only 12 questions out of 13 questions could be kept for factor rotation. Based on results of table 3, two factors are extracted by varimax rotation, based on $53.8 \%$ of the explained variance with Eigenvalues exceeded one. To summarize the results of EFA between perceived benefits constructs: (1) BH7 should be classified under factor BS; (2) one questions need to be deleted from this instrument (BS2) due to factor loading being less than 0.4. BH7: adherence to treatment originally classified under perceived benefits from health outcomes were loaded onto social outcomes group. Initially this item was grouped under health outcomes based on pilot test and literature review, however, respondent view this item as part of social outcomes.

Table 3 EFA results for perceived benefits of OHE construct

\begin{tabular}{|c|c|c|c|c|c|c|}
\hline \multirow[b]{2}{*}{ Construct } & \multirow{2}{*}{$\begin{array}{l}\text { Item in } \\
\text { scale }\end{array}$} & \multirow{2}{*}{\multicolumn{2}{|c|}{$\begin{array}{c}\text { Internal consistency } \\
\text { Cronbach’s } \\
\text { Alpha }\end{array}$}} & \multicolumn{2}{|c|}{ Unidimensionality } & \multirow[b]{2}{*}{ Eigenvalues } \\
\hline & & & & $\begin{array}{c}\text { Factor } \\
\text { loading }\end{array}$ & $\begin{array}{c}\text { Variance } \\
\text { explained }\end{array}$ & \\
\hline \multirow[t]{7}{*}{ 1a } & & \multicolumn{2}{|c|}{.892} & & \multirow[t]{7}{*}{$47.28 \%$} & \multirow[t]{7}{*}{6.15} \\
\hline & BH1 & .673 & .881 & .646 & & \\
\hline & BH2 & .754 & .868 & .744 & & \\
\hline & ВH3 & .755 & .867 & .730 & & \\
\hline & BH4 & .749 & .868 & .743 & & \\
\hline & BH5 & .765 & .865 & .795 & & \\
\hline & BH6 & .616 & .890 & .546 & & \\
\hline \multirow[t]{7}{*}{$2 b$} & & \multicolumn{2}{|c|}{.853} & & \multirow[t]{7}{*}{$6.48 \%$} & \multirow[t]{7}{*}{.85} \\
\hline & BS1 & .604 & .835 & .538 & & \\
\hline & BS3 & .659 & .826 & .805 & & \\
\hline & BS4 & .685 & .821 & .785 & & \\
\hline & BS5 & .566 & .844 & .444 & & \\
\hline & BS6 & .702 & .817 & .582 & & \\
\hline & BH7 & .630 & .831 & .514 & & \\
\hline
\end{tabular}

In order to look if there is any differences in both groups perception towards OHE constructs, repeated measurement t-test were used to determine whether there is significant difference between two sets of scores [47]. 
Table 4 Independent Samples Test

\begin{tabular}{|c|c|c|c|c|c|c|c|c|c|c|}
\hline & $\begin{array}{r}\text { Leve } \\
\text { Test } \\
\text { Equal } \\
\text { Varia } \\
\end{array}$ & $\begin{array}{l}\text { ne's } \\
\text { for } \\
\text { ty of } \\
\text { nces } \\
\end{array}$ & \multicolumn{7}{|c|}{ t-test for Equality of Means } \\
\hline & & \multirow[t]{2}{*}{$\mathrm{F}$} & \multirow[t]{2}{*}{ Sig. } & \multirow[t]{2}{*}{$\mathrm{t}$} & \multirow[t]{2}{*}{$\mathrm{df}$} & \multirow[t]{2}{*}{$\begin{array}{c}\text { Sig. } \\
\text { (2-tailed) }\end{array}$} & \multirow[t]{2}{*}{$\begin{array}{c}\text { Mean } \\
\text { Difference }\end{array}$} & \multirow[t]{2}{*}{$\begin{array}{l}\text { Std. Error } \\
\text { Difference }\end{array}$} & \multicolumn{2}{|c|}{$\begin{array}{l}\text { 95\% Confidence } \\
\text { Interval of the } \\
\text { Difference }\end{array}$} \\
\hline & & & & & & & & & Lower & Upper \\
\hline \multirow{2}{*}{$\mathrm{BH}$} & $\begin{array}{l}\text { Equal } \\
\text { variances } \\
\text { assumed }\end{array}$ & 2.654 & .105 & 1.020 & 213 & .309 & .08585 & .08418 & -.08008 & .25178 \\
\hline & $\begin{array}{l}\text { Equal } \\
\text { variances } \\
\text { not } \\
\text { assumed }\end{array}$ & & & 1.105 & 184.277 & .271 & .08585 & .07768 & -.06741 & .23910 \\
\hline \multirow{2}{*}{ BS } & $\begin{array}{l}\text { Equal } \\
\text { variances } \\
\text { assumed }\end{array}$ & 1.965 & .162 & 1.463 & 213 & .145 & .13420 & .09173 & -.04660 & .31501 \\
\hline & $\begin{array}{l}\text { Equal } \\
\text { variances } \\
\text { not } \\
\text { assumed } \\
\end{array}$ & & & 1.553 & 174.708 & .122 & .13420 & .08644 & -.03640 & .30480 \\
\hline
\end{tabular}

According to the results that can be seen that there is no significance difference between the perceived benefits of health and social effect on health professionals and health consumers such as patients and carer. Health professionals opinion on $\mathrm{OHE}$ also as perceptions of technology use could be variable among health professionals [48].

\section{Discussions}

One limitation of this study is perceived benefits of OHE were identified through survey from health consumers and health professional. Longitudinal study conducted based on actual health outcome measures will reflect the actual benefits of OHE. Nevertheless, this study identified consumers' opinions on OHE. The study indicated consumers have positive attitudes towards use of OHE.

This study has the practical implication as the study identified OHE effectiveness, which definitely can assist health practitioners on health education, which can lead to better health outcome. Conventional health education to patient is provided by healthcare practitioners, but this takes time and may not be convenient for the patient. Since the patient may be adjusting to the new disease, not all of the information provided at the time will necessarily be absorbed by the patient at that time of provision [12]. This is because of the shock which is associated with learning about a particular condition that one suffers from. OHE can assist healthcare providers in providing patient education; this will enable education programs to be viewed by patients at any convenient moment. They can revisit the sites and will be able to absorb more information when they feel more relaxed and calm. This will encourage patients to be more involved in their own healthcare which in turn will enhance communication between patients and health 
professionals [49]. The study also demonstrated that health professionals positive opinions on OHE.

Barriers to using OHE will need to consider in creating OHE such as, low patient computer skills, unwillingness to use the technology, poor architectural and technical designs. Without appropriate information technology skills, patients cannot connect to the Internet let alone access education materials from the Web. However, one cannot argue that if OHE is accessible, it could assist in healthcare management by the benefits that have been identified. These barriers could be overcome by having more accessible OHE through smart phone and mobile applications. Several mobile applications have been available recently for health promotion and health intervention [14]. Increasing use of Facebook and social network have been another option for providing health education material to patients online [50]. More user friendly applications such as having persuasive technology in healthcare would motivate consumers to use the OHE. Health education websites tailored according to user needs will increase uptake of OHE [51]. Studies also indicated that more uptake of OHE, if these OHE sites are introduced to patients from their healthcare providers [52].

OHE is an effective strategy for presenting information and improving knowledge outcomes among patients. Improving patient emotional state and patient satisfaction for persons with chronic diseases through OHE will maximise health outcome. Social supports can be provided effectively using online computer support groups. Patient confidence and adherence to treatments are also beneficial for patients who effectively use OHE. Findings have shown that health education and knowledge acquisition can be improved through OHE with chronic diseases. The findings from this study also reinforced the benefits identified in previous studies on computer aided health education to psychiatric patients [53].

As health education is to motivate consumers to change their behaviour towards healthcare and perceptions of consumers on health education would play an important role in health education. Moreover, opinions on health professionals have been similar on benefits of OHE. It could be seen that health professionals have been familiar with online applications for professional development and education [54].

Aside from all the benefits of online health education, one cannot ignore the importance of getting the right material for health education in providing accurate health information and right design to the public, especially those who suffer from chronic diseases. Therefore, design features of OHE should be studied and mapped with the benefits defined in this study.

\section{Conclusion}

The analysis of the literature has identified a set of 12 potential benefits of OHE which had been used to understand the perceptions of the effectiveness of OPE sites. These 12 potential benefits have been validated with health practitioners, patients with chronic disease and care providers.

This research identifies and acknowledges the potential benefits of OHE for all consumers. To maximize the benefits of OHE, it may be necessary not only for decision makers to exert shifts in their thinking and strategies, but also to instigate reliable management in order to harmonize the processes of policy and decision 
making for the benefit of the consumers. In other words, decision makers need to make user-benefits a top priority during the process of decision-making. Disparities in terms of access to OHE, healthcare, and technology may make it harder for consumers and patients to achieve their health-related goals. The results from this study also help Health Informatics body of knowledge as indicating the role of OHE can help in improving chronic disease management.

\section{Conflict of Interest}

The authors declare that there is no conflict of Interest.

\section{References}

1. Hassan NM, Win KT, Hyland P Exploring Design Features and Benefits of Online Patient Education (OPE) Sites for Chronic Diseases. In: System Sciences (HICSS), 2013 46th Hawaii International Conference on, 7-10 Jan. 2013 2013. pp 2454-2463. doi:10.1109/HICSS.2013.215

2. Win KT (2010) Implementing patient accessible health information site for diabetes management. Paper presented at the Pacific Asia Conference on Information Systems, Taiwan: National Taiwan University,

3. Mollaoğlu M, Beyazit E (2009) Influence of diabetic education on patient metabolic control. Applied Nursing Research 22 (3):183-190

4. Amsberg S, Anderbro T, Wredling R, Lisspers J, Lins PE, Adamson U, Johansson UB (2009) A cognitive behavior therapy-based intervention among poorly controlled adult type 1 diabetes patients-A randomized controlled trial. Patient Education and Counseling 77 (1):72-80

5. Mohiyeddini C, Pauli R, Bauer S (2009) The role of emotion in bridging the intention-behaviour gap: The case of sports participation. Psychology of Sport and Exercise 10 (2):226-234

6. Boyer C, Selby M, Scherrer JR, Appel RD (1998) The Health On the Net Code of Conduct for medical and health Websites. Computers in Biology and Medicine 28 (5):603-610

7. Washington TA, Fanciullo GJ, Sorensen JA, Baird JC (2008) Quality of chronic pain websites. Pain Medicine 9 (8):994-1000

8. Runge C, Lecheler J, Horn M, Tews J-T, Schaefer M (2006) Outcomes of a Web-based patient education program for asthmatic children and adolescents. Chest 129 (3):581-593

9. Bull SS, Gaglio B, McKay HG, Glasgow RE (2005) Harnessing the potential of the internet to promote chronic illness self-management: diabetes as an example of how well we are doing. Chronic Illness 1 (2):143-155

10. Kerr C, Murray E, Stevenson F, Gore C, Nazareth I (2006) Internet interventions for long-term conditions: patient and caregiver quality criteria.[see comment]. Journal of Medical Internet Research 8 (3):e13

11. Thakurdesai PA, Kole PL, Pareek RP (2004) Evaluation of the quality and contents of diabetes mellitus patient education on Internet. Patient Education \& Counseling 53 (3):309-313

12. Casebeer L, Allison J, Spettell CM (2002) Designing tailored Web-based instruction to improve practicing physicians' chlamydial screening rates. Academic Medicine 77 (9):929 
13. Hjelm K, Berntorp K, Frid A, Åberg A, Apelqvist J (2008) Beliefs about health and illness in women managed for gestational diabetes in two organisations. Midwifery 24 (2):168-182

14. Bert F, Giacometti M, Gualano M, Siliquini R (2013) Smartphones and Health Promotion: A Review of the Evidence. J Med Syst 38 (1):1-11. doi:10.1007/s10916-013-9995-7

15. Nutbeam D (2000) Health literacy as a public health goal: a challenge for contemporary health education and communication strategies into the 21st century. Health Promot Int 15 (3):259-267. doi:10.1093/heapro/15.3.259

16. Ellis SE, Speroff T, Dittus RS, Brown A, Pichert JW, Elasy TA (2004) Diabetes patient education: a meta-analysis and meta-regression. Patient Education and Counseling 52 (1):97-105

17. Singh N, Armstrong DG, Lipsky BA (2005) Preventing foot ulcers in patients with diabetes. JAMA 293 (2):217-228

18. Homer C, Susskind O, Alpert HR, Owusu MPM, Celestina, Schneider L, Rappaport LA, Rubin DH (2000) An Evaluation of an Innovative Multimedia Educational Software Program for Asthma Management: Report of a $\begin{array}{lllll}\text { Randomized, Controlled } & \text { Trial. Pediatrics } 106 & \text { (1):210-215. }\end{array}$ doi:10.1542/peds.106.1.S1.210

19. Ball MJ, Lillis J (2001) E-health: transforming the physician/patient relationship. International Journal of Medical Informatics 61 (1):1-10

20. Borowitz SM, Ritterband L (2001) Using the Internet to teach parents and children about constipation and encopresis. Medical Informatics \& the Internet in Medicine 26 (4):283-295

21. Fleisher L, Buzaglo J, Collins M, Millard J, Miller SM, Egleston BL, Solarino N, Trinastic J, Cegala DJ, Benson Iii AB, Schulman KA, Weinfurt KP, Sulmasy D, Diefenbach MA, Meropol NJ (2008) Using health communication best practices to develop a web-based provider-patient communication aid: The CONNECT(TM) study. Patient Education and Counseling 71 (3):378-387

22. Abbott SA (1998) The Benefits of Patient Education. Volume 21(5) (September/October 1998):207-209

23. Ullrich PFJMDa, Vaccaro ARMD (2002) Patient Education on the Internet: Opportunities and Pitfalls. Spine 27 (7):E185-E188

24. Dolor RJ, Yancy WS, Jr., Owen WF, Matchar DB, Samsa GP, Pollak KI, Lin P-H, Ard JD, Prempeh M, McGuire HL, Batch BC, Fan W, Svetkey LP (2009) Hypertension Improvement Project (HIP): study protocol and implementation challenges. Trials [Electronic Resource] 10:13

25. Viele CS (2003) Diagnosis, treatment, and nursing care of acute leukemia. Seminars in Oncology Nursing 19 (2):98-108

26. Levin-Zamir D, Peterburg Y (2001) Health literacy in health systems: perspectives on patient self-management in Israel. Health Promotion International 16 (1):87-94

27. Azar M, Gabbay R (2009) Web-based management of diabetes through glucose uploads: Has the time come for telemedicine? Diabetes Research and Clinical Practice 83 (1):9-17

28. Cabana MD, Le TT (2005) Challenges in asthma patient education. Journal of Allergy and Clinical Immunology 115 (6):1225-1227

29. Gremeaux V, Coudeyre E (2010) The Internet and the therapeutic education of patients: A systematic review of the literature. Annals of Physical and Rehabilitation Medicine 53 (10):669-692 
30. Oenema A, Brug J, Lechner L (2001) Web-based tailored nutrition education: results of a randomized controlled trial. Health Education Research 16 (6):647660. doi:10.1093/her/16.6.647

31. Lee S, Koubek RJ (2010) The effects of usability and web design attributes on user preference for e-commerce web sites. Computers in Industry 61 (4):329-341

32. Bass SB, Ruzek SB, Gordon TF, Fleisher L, McKeown-Conn N, Moore D (2006) Relationship of Internet health information use with patient behavior and self-efficacy: Experiences of newly diagnosed cancer patients who contact the National Cancer Institute's Cancer Information Service. Journal of Health Communication 11 (2):219-236

33. Nahm ES, Blum K, Scharf B, Friedmann E, Thomas S, Jones D, Gottlieb SS (2008) Exploration of patients' readiness for an ehealth management program for chronic heart failure: A preliminary study. Journal of Cardiovascular Nursing 23 (6):463-471

34. Potts HWW, Wyatt JC (2002) Survey of doctors' experience of patients using the Internet. Journal of Medical Internet Research 4 (1):e5

35. Allen M, Iezzoni LI, Huang A, Huang L, Leveille SG (2007) Internet-based coaching to improve patient-clinician communication in primary care. AMIA Annual Symposium Proceedings/AMIA Symposium.:861

36. Coulson NS, Shaw RL (2013) Nurturing health-related online support groups: Exploring the experiences of patient moderators. Computers in Human Behavior 29 (4):1695-1701

37. Singh B, Mallika V, Goswami B (2007) Metabolic syndrome: Diagnosis, potential markers and management-an update. Clinica Chimica Acta 380 (1-2):412

38. Camerini L, Camerini A-L, Schulz PJ (2012) Do participation and personalization matter? A model-driven evaluation of an Internet-based patient education intervention for fibromyalgia patients. Patient Education and Counseling

39. Mosca L, Linfante AH, Benjamin EJ, Berra K, Hayes SN, Walsh BW, Fabunmi RP, Kwan J, Mills T, Simpson SL (2005) National study of physician awareness and adherence to cardiovascular disease prevention guidelines. Circulation 111 (4):499-510

40. Heart Failure Society of A (2006) Section 8: Disease Management in Heart Failure. Journal of Cardiac Failure 12 (1):e58-e69

41. Bussey-Smith KL, Rossen RD (2007) A systematic review of randomized control trials evaluating the effectiveness of interactive computerized asthma patient education programs. Annals of Allergy, Asthma \& Immunology 98 (6):507-516

42. Whitten P, Buis L, Love B (2007) Physician-patient e-visit programs: Implementation and appropriateness. Disease Management and Health Outcomes 15 (4):207-214

43. Weinert C, Cudney S, Hill W (2008) Health knowledge acquisition by rural women with chronic health conditions: A tale of two Web approaches. Australian Journal of Rural Health 16 (5):302-307

44. Campbell HS, Phaneuf MR, Deane K (2004) Cancer peer support programs-do they work? Patient Education and Counseling 55 (1):3-15

45. Hong Y, Peña-Purcel NC, Ory MG (2012) Outcomes of online support and resources for cancer survivors: A systematic literature review. Patient Education and Counseling 86 (3):288-296 
46. Abbott SA (1998) The Benefits of Patient Education. Gastroenterology Nursing 21 (5):207-209

47. Coakes SJ (2005) SPSS : analysis without anguish : version 12.0 for Windows. Milton, Qld, John Wiley \& Sons Australia

48. Maarop N, Win K (2012) Understanding the Need of Health Care Providers for Teleconsultation and Technological Attributes in Relation to The Acceptance of Teleconsultation in Malaysia: A Mixed Methods Study. J Med Syst 36 (5):2881-2892. doi:10.1007/s10916-011-9766-2

49. Win K, Susilo W, Mu Y (2006) Personal Health Record Systems and Their Security Protection. J Med Syst 30 (4):309-315. doi:10.1007/s10916-006-9019-y 50. Zaidan AA, Zaidan BB, Kadhem Z, Larbani M, Lakulu MB, Hashim M (2015) Challenges, Alternatives, and Paths to Sustainability: Better Public Health Promotion Using Social Networking Pages as Key Tools. J Med Syst 39 (2):1-14. doi:10.1007/s10916-015-0201-y

51. Hassan NM, Win KT Exploring Design Features (Web Environment) and Perceived Benefits (Incentives) of Online Patient Education (OPE) Sites for Chronic Diseases. In: International Conference on Emerging Trends in Computer Science \& Information Technology, Kuala Lumpur, Malaysia, 2013. pp 292-298 52. Owens BH, Robbins KC (1996) CHESS: comprehensive health enhancement support system for women with breast cancer. Plastic surgical nursing : official journal of the American Society of Plastic and Reconstructive Surgical Nurses 16 (3):172-175, 182

53. Tseng K-J, Liou T-H, Chiu H-W (2012) Development of a Computer-Aided Clinical Patient Education System to Provide Appropriate Individual Nursing Care for Psychiatric Patients. J Med Syst 36 (3):1373-1379. doi:10.1007/s10916010-9599-4

54. Luanrattana R, Win K, Fulcher J, Iverson D (2012) Mobile Technology Use in Medical Education. J Med Syst 36 (1):113-122. doi:10.1007/s10916-010-9451-X 